\title{
Dysregulation of Transcription Factor Activity during Formation of Cancer-Associated Fibroblasts
}

\author{
Przemysław Kapusta ${ }^{1}{ }^{\mathbb{B}}$, Joanna Dulińska-Litewka ${ }^{2}{ }^{\mathbb{B}}$, Justyna Totoń-Żurańska ${ }^{1}{ }^{\mathbb{D}}$, \\ Agnieszka Borys ${ }^{1}{ }^{1}$, Paweł S. Konieczny ${ }^{1}$, Paweł P. Wołkow ${ }^{1,3, *,+}$ and Michał T. Seweryn $1,4, *, \dagger$ \\ 1 Center for Medical Genomics OMICRON, Jagiellonian University Medical College, 31-034 Kraków, Poland; \\ przemyslaw.kapusta@uj.edu.pl (P.K.); justyna.toton-zuranska@uj.edu.pl (J.T.-Ż.); \\ agnieszka.borys@uj.edu.pl (A.B.); pawel.konieczny@outlook.pl (P.S.K.) \\ 2 Chair of Medical Biochemistry, Jagiellonian University Medical College, 31-034 Kraków, Poland; \\ joanna.dulinska-litewka@uj.edu.pl \\ 3 Department of Pharmacology, Jagiellonian University Medical College, 31-531 Kraków, Poland \\ 4 Faculty of Mathematics and Computer Science, University of Łódź, 90-238 Łódź, Poland \\ * Correspondence: pawel.wolkow@uj.edu.pl (P.P.W.); michal.seweryn@wmii.uni.lodz.pl (M.T.S.) \\ + These authors contributed equally to this work.
}

Received: 20 October 2020; Accepted: 17 November 2020; Published: 19 November 2020

\begin{abstract}
The reciprocal interactions between cancer cells and the quiescent fibroblasts leading to the activation of cancer-associated fibroblasts (CAFs) serve an important role in cancer progression. Here, we investigated the activation of transcription factors (TFs) in prostate fibroblasts (WPMY cell line) co-cultured with normal prostate or tumorous cells (RWPE1 and RWPE2 cell lines, respectively). After indirect co-cultures, we performed mRNA-seq and predicted TF activity using mRNA expression profiles with the Systems EPigenomics Inference of Regulatory Activity (SEPIRA) package and the GTEx and mRNA-seq data of 483 cultured fibroblasts. The initial differential expression analysis between time points and experimental conditions showed that co-culture with normal epithelial cells mainly promotes an inflammatory response in fibroblasts, whereas with the cancerous epithelial, it stimulates transformation by changing the expression of the genes associated with microfilaments. TF activity analysis revealed only one positively regulated TF in the RWPE1 co-culture alone, while we observed dysregulation of $45 \mathrm{TFs}$ ( 7 decreased activity and 38 increased activity) uniquely in co-culture with RWPE2. Pathway analysis showed that these 45 dysregulated TFs in fibroblasts co-cultured with RWPE2 cells may be associated with the RUNX1 and PTEN pathways. Moreover, we showed that observed dysregulation could be associated with FER1L4 expression. We conclude that phenotypic changes in fibroblast responses to co-culturing with cancer epithelium result from orchestrated dysregulation of signaling pathways that favor their transformation and motility rather than proinflammatory status. This dysregulation can be observed both at the TF and transcriptome levels.
\end{abstract}

Keywords: cancer-associated fibroblasts (CAFs); prostate cancer; long non-coding RNA (lncRNA); FER1L4; transcription factors (TFs)

\section{Introduction}

Interactions between cancer cells and cancer-associated fibroblasts (CAFs) play an important role in promoting tumorigenesis, extracellular matrix (ECM) remodeling and tumor invasion, as well as the induction of metastasis $[1,2]$. The molecular mechanisms leading the transition from quiescent fibroblasts to activated CAFs are, however, still unclear. CAFs are characterized by a contractile phenotype, associated with the expression of $\alpha$-smooth muscle actin ( $\alpha$ SMA), similar to activated 
fibroblasts responsible for wound healing (i.e., myofibroblasts). [3,4]. The well-established activating signals for myofibroblast differentiation are transforming growth factor beta (TGF- $\beta$ ) family ligands, which, in cancer, might promote CAF activation $[5,6]$ and tumor growth and progression $[7,8]$.

Increasing evidence suggests that CAFs are a heterogeneous population and have diverse functions depending on tumor developmental stage and tissue microenvironment [9]. Elyada et al., in their single-cell RNA sequencing experiment, showed the existence of myofibroblastic and inflammatory CAFs in human pancreatic ductal adenocarcinoma tumors, each having unique gene signatures in vivo [10]. Costa et al. used multicolor flow cytometry to identify four subtypes of CAFs associated with breast cancer, with distinct properties and levels of activation [11]. Recent discoveries identified transforming growth factor $\beta$ (TGF- $\beta$ ) and interleukin 1 (IL-1) as tumor-secreted ligands that promote CAFs heterogeneity [12]. Moreover, it was shown that activation of fibroblasts by cancer cells induced self-sustaining stromal cell-derived factor 1 (SDF1/CXCL12) and TGF- $\beta$ autocrine signaling pathways to promote the formation of CAFs with increased $\alpha$-SMA expression levels [13]. The activated TGF- $\beta$ receptor complex initiates several downstream cascades, including the canonical Smad2/3 signaling pathway and non-canonical pathways, such as phosphoinositide 3-kinases (PI3K/AKT), Mitogen-activated protein kinase (MAPK) pathways (extracellular signal regulated kinase (ERK), Jun kinase (JNK), and p38 MAPK), as well as nuclear factor kappa-light-chain-enhancer of activated B cells (NF-KB) $[14,15]$. Moreover, transversal signaling at the SMAD level integrates signals from other pathways, e.g., Notch, Wnt/ $\beta$-catenin, TNF- $\alpha$ and epidermal growth factor receptor (EGFR) [16]. The heterogeneity of the pathways engaged in the conversion of normal fibroblasts into CAFs may be associated with the unique functions of CAF subpopulations in different types of tumors. [17]. This suggests that several cytokines or chemokines may be involved in the conversion of normal fibroblasts into CAFs, and some of these form a feedback loop between cancer cells and CAFs.

Therefore, we sought to perform indirect co-cultures of normal prostate fibroblasts (WPMY1) with either normal (RWPE1) or cancerous (RWPE2) prostate epithelial cells at two time points, to catch a glimpse of the feedback loop between CAFs and normal or tumorous cells. We also set to derive a dynamic landscape of the regulatory activity of transcription factors (TFs) based on the mRNA sequencing at those time points. The results of our work point towards the identification of early and potentially causal pathways in CAF transformation in this unique model.

\section{Results}

\section{1. mRNA-seq Gene Expression Analysis}

The pairwise comparison of WR1 (WPMY1 + RWPE1) and WR2 (WPMY1 + RWPE2) after $6 \mathrm{~h}$ co-culture did not show any statistical significance. After $24 \mathrm{~h}$, we found 107 differently expressed (DE) genes-46 downregulated and 61 upregulated in WR1 condition (Supplementary Table S1). In the comparison between the control (CTRL) (WPMY1 alone) and WR2 conditions, after $24 \mathrm{~h}$, we found only one DE gene, KLF9 $\left(\operatorname{logFC}=1.15, p=1.64 \times 10^{-8}\right.$, adj. $\left.p=2.6 \times 10^{-4}\right)$. At the same time, KLF9 was also overexpressed in the WR1 condition (as compared to the CTRL group) (logFC $=1.19, p=9.57 \times 10^{-9}$, adj. $p=7.61 \times 10^{-5}$, Supplementary Material 1$)$. After $24 \mathrm{~h}$, we detected two genes differentially expressed between the WR1 and WR2 groups with false discovery rate (FDR) $<0.1$. The first, $M M P 3\left(\log \mathrm{FC}=-1.53, p=5.10 \times 10^{-6}\right.$, adj. $\left.p=8.05 \times 10^{-2}\right)$, was overexpressed in the WR1 group, whereas the second, FER1L4 $\left(\log F C=1.34, p=1.01 \times 10^{-5}\right.$, adj. $\left.p=8.05 \times 10^{-2}\right)$, was overexpressed in the WR2 group.

Subsequently, we aimed to identify differentially expressed RNAs between the 6 and $24 \mathrm{~h}$ incubation period in each of the experimental conditions separately. In the CTRL group (WPMY1 24-6 h), we observed 124 downregulated and 432 upregulated genes. In the WR1 group (WPMY1 + RWPE1 24-6 h), we observed 327 downregulated and 729 upregulated genes, and in the WR2 group (WPMY1 + RWPE2 24-6 h), 278 and 1021, respectively (Figure 1). Detailed information about DE genes in each condition is presented in Supplementary Table S2. 

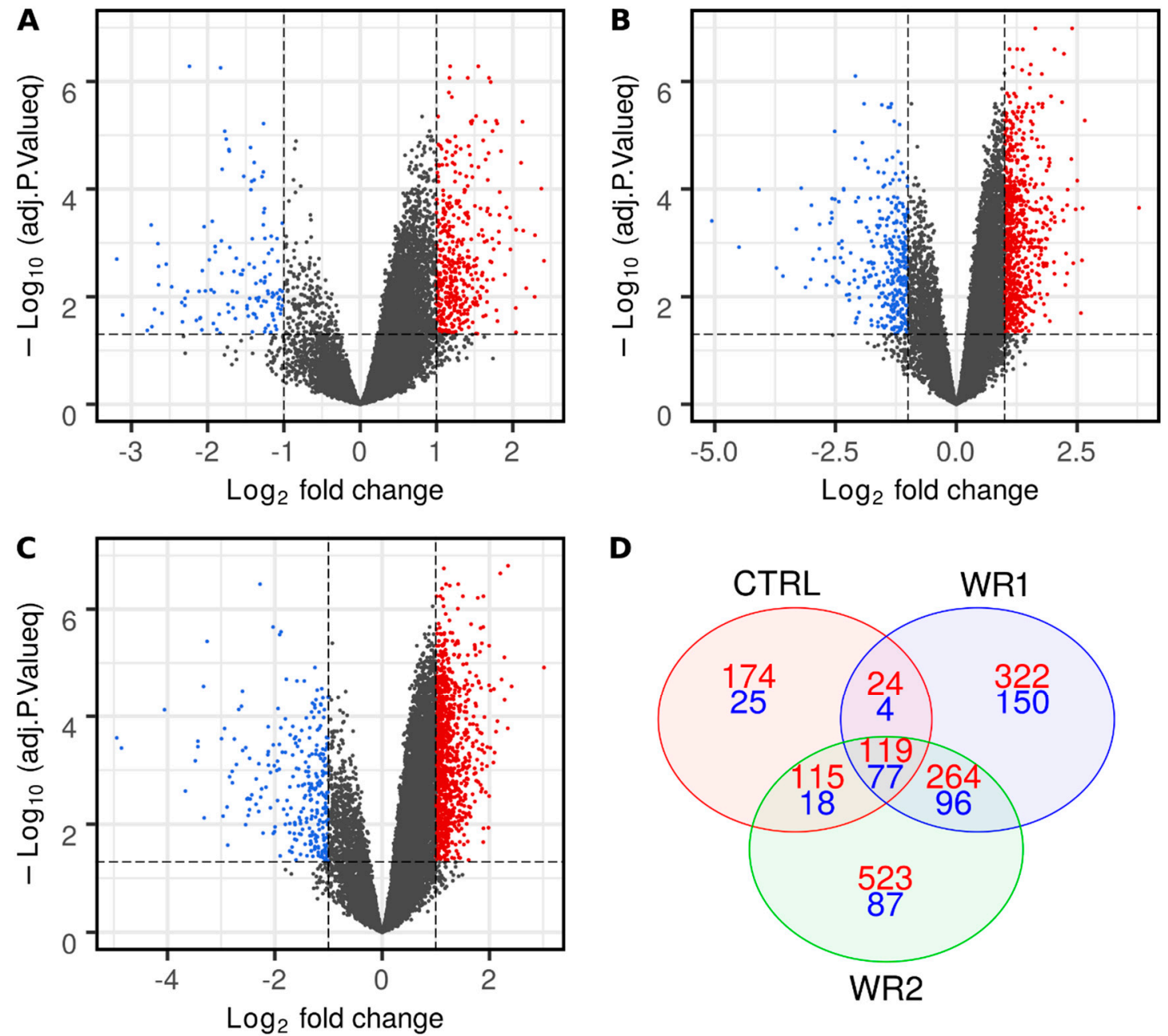

D

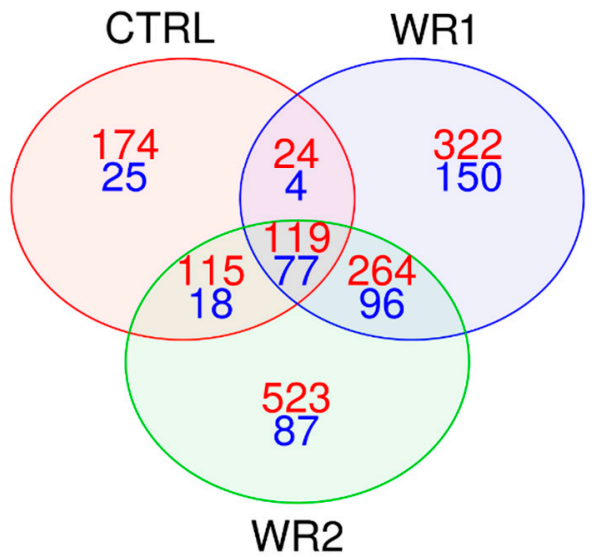

Figure 1. Differentially expressed (DE) gene analysis between 6 and $24 \mathrm{~h}$ in each condition separately. Volcano plots represents the distribution of DE genes between 6 and $24 \mathrm{~h}$ for the control (CTRL) (A), WR1 (B) and WR2 (C) groups. Lines separate $\log F C>1$ and adj. $p$ value $<0.05$. Venn diagram of the distribution of DE genes between 6 and $24 \mathrm{~h}$ in each condition with $\log \mathrm{FC}>1$ (D). Red color represents upregulated genes, and blue, downregulated genes.

In what follows, we performed a pathway enrichment analysis based on the unique DE results in the WR1 and WR2 groups, separately. We received 98 and 70 significant pathways for the WR1 and WR2 conditions, respectively (Supplementary Table S3). The top 10 enriched biological processes are presented in Table 1. 
Table 1. Top10 gene ontologies (GOs) for gene enrichment analysis of DE genes with $\log F C>1$ unique for WR1 and WR2 conditions.

\begin{tabular}{|c|c|c|c|c|}
\hline Condition & GO.ID & Term & $p$-Value & Annotated_Genes \\
\hline \multirow{10}{*}{ WR1 } & GO:0019221 & $\begin{array}{l}\text { Cytokine-mediated } \\
\text { signaling pathway }\end{array}$ & $2.50 \times 10^{-4}$ & $\begin{array}{c}\text { CXCL2, IL12RB1, CD40, TRADD, } \\
\text { CSF3, PTPN6, GHR, TNFRSF8, } \\
\text { MT2A, CD70, LCN2, MMP3, } \\
\text { CXCL8, PALM3 }\end{array}$ \\
\hline & GO:0071222 & $\begin{array}{l}\text { Cellular response to } \\
\text { lipopolysaccharide }\end{array}$ & $8.30 \times 10^{-4}$ & $\begin{array}{c}\text { CXCL2, CSF3, LCN2, ANKRD1, } \\
\text { CXCL8, NFKBIL1 }\end{array}$ \\
\hline & GO:0015804 & neutral amino acid transport & $1.22 \times 10^{-3}$ & SLC7A5, RGS4, SLC6A9 \\
\hline & GO:0006855 & $\begin{array}{c}\text { Drug } \\
\text { transmembrane transport }\end{array}$ & $2.12 \times 10^{-3}$ & $\begin{array}{c}\text { SLC7A5, RGS4, } \\
\text { SLC47A1, SLC25A18 }\end{array}$ \\
\hline & GO:0071356 & $\begin{array}{l}\text { Cellular response to tumor } \\
\text { necrosis factor }\end{array}$ & $2.51 \times 10^{-3}$ & $\begin{array}{c}\text { CD40, TRADD, TNFRSF8, CD70, } \\
\text { LCN2, ANKRD1, CXCL8 }\end{array}$ \\
\hline & GO:0019724 & B cell-mediated immunity & $3.50 \times 10^{-3}$ & CD40, PTPN6, CD70, C4A \\
\hline & GO:0009605 & $\begin{array}{l}\text { Response to } \\
\text { external stimulus }\end{array}$ & $3.59 \times 10^{-3}$ & $\begin{array}{c}\text { TYMP, TNC, ASNS, CXCL2, } \\
\text { IGSF9, IL12RB1, PCK2, CD40, } \\
\text { TRADD, CORO1A, AKNA, CSF3, } \\
\text { STC2, NR4A3, TNFRSF8, MT2A, } \\
\text { NPAS1, MYPN, LYG1, EPHA1, } \\
\text { LCN2, ANKRD1, MMP3, MARS, } \\
\text { CXCL8, NUPR1, PALM3, } \\
\text { NFKBIL1, C4A }\end{array}$ \\
\hline & GO:0019730 & $\begin{array}{c}\text { Antimicrobial } \\
\text { humoral response }\end{array}$ & $3.67 \times 10^{-3}$ & CXCL2, LCN2, CXCL8 \\
\hline & GO:0061469 & $\begin{array}{c}\text { Regulation of type B } \\
\text { pancreatic cell proliferation }\end{array}$ & $4.12 \times 10^{-3}$ & NR4A3, NUPR1 \\
\hline & GO:0032354 & $\begin{array}{l}\text { Response to } \\
\text { follicle-stimulating hormone }\end{array}$ & $4.12 \times 10^{-3}$ & ASNS, PAPPA \\
\hline \multirow{10}{*}{ WR2 } & GO:0001541 & $\begin{array}{c}\text { Ovarian } \\
\text { follicle development }\end{array}$ & $3.30 \times 10^{-5}$ & DMC1, LFNG, VGF, SOD1, KIT \\
\hline & GO:0045987 & $\begin{array}{c}\text { Positive regulation of } \\
\text { smooth muscle contraction }\end{array}$ & $6.50 \times 10^{-4}$ & TACR2, GHRL, KIT \\
\hline & GO:0060285 & $\begin{array}{l}\text { Cilium-dependent } \\
\text { cell motility }\end{array}$ & $9.90 \times 10^{-4}$ & DNAH7, CFAP54, CFAP57 \\
\hline & GO:0003341 & Cilium movement & $3.67 \times 10^{-3}$ & DNAH7, MAATS1, CFAP54 \\
\hline & GO:0042745 & Circadian sleep/wake cycle & $3.89 \times 10^{-3}$ & GHRL, NLGN1 \\
\hline & GO:0099175 & $\begin{array}{l}\text { Regulation of post-synapse } \\
\text { organization }\end{array}$ & $4.04 \times 10^{-3}$ & GHRL, NLGN1, GAP43, FZD9 \\
\hline & GO:0045747 & $\begin{array}{l}\text { Positive regulation of Notch } \\
\text { signaling pathway }\end{array}$ & $4.29 \times 10^{-3}$ & LFNG, KIT, MESP1 \\
\hline & GO:1900029 & $\begin{array}{l}\text { Positive regulation of } \\
\text { ruffle assembly }\end{array}$ & $4.64 \times 10^{-3}$ & CARMIL2, NLGN1 \\
\hline & GO:0045986 & $\begin{array}{l}\text { Negative regulation of } \\
\text { smooth muscle contraction }\end{array}$ & $4.64 \times 10^{-3}$ & $C A L C R L, S O D 1$ \\
\hline & GO:0051290 & $\begin{array}{c}\text { Protein } \\
\text { heterotetramerization }\end{array}$ & $4.96 \times 10^{-3}$ & NLGN1, S100A10, HIST1H4A \\
\hline
\end{tabular}

GO.ID-The Gene Ontology Identifier.

\subsection{Estimation of Transcript Factors Activity}

Based on the mRNA expression profiles from sequencing, we estimated TF activity in each experimental condition. Our analysis did not show any statistically significant TFs with FDR $<0.05$ neither at the $6 \mathrm{~h}$, nor the $24 \mathrm{~h}$ co-culture. Yet, there were some significant TFs with nominal $p$-value $<0.05$. In particular, after $6 \mathrm{~h}$, we found only $4 \mathrm{TFs}$ ( 1 negatively and 3 positively regulated) 
in comparison with CTRL and WR2 and 1 negatively regulated TF between WR1 and WR2. After $24 \mathrm{~h}$ of co-culture, we found $13 \mathrm{TFs}$ between CTRL and WR1 (7 negatively and 6 positively regulated), 2 positively regulated TFs between CTRL and WR2 and 3 TFs between WR1 and WR2 (1 negatively and 2 positively regulated). Detailed information about the results of these comparisons is in Supplementary Material 4. Since the FDR correction resulted in no significant results, we decided to show only nominally significant results for WR1 vs. WR2 comparisons, as they are most important (Figure 2). Our TF activity analysis suggest that activation of RNF4 and SNAPC1 may be associated with normal tissue growth (co-culture with RWPE1), whereas activation of TFs such as THRAP3 and GTF3C1 could be associated with tumorigenic cells (RWPE2).
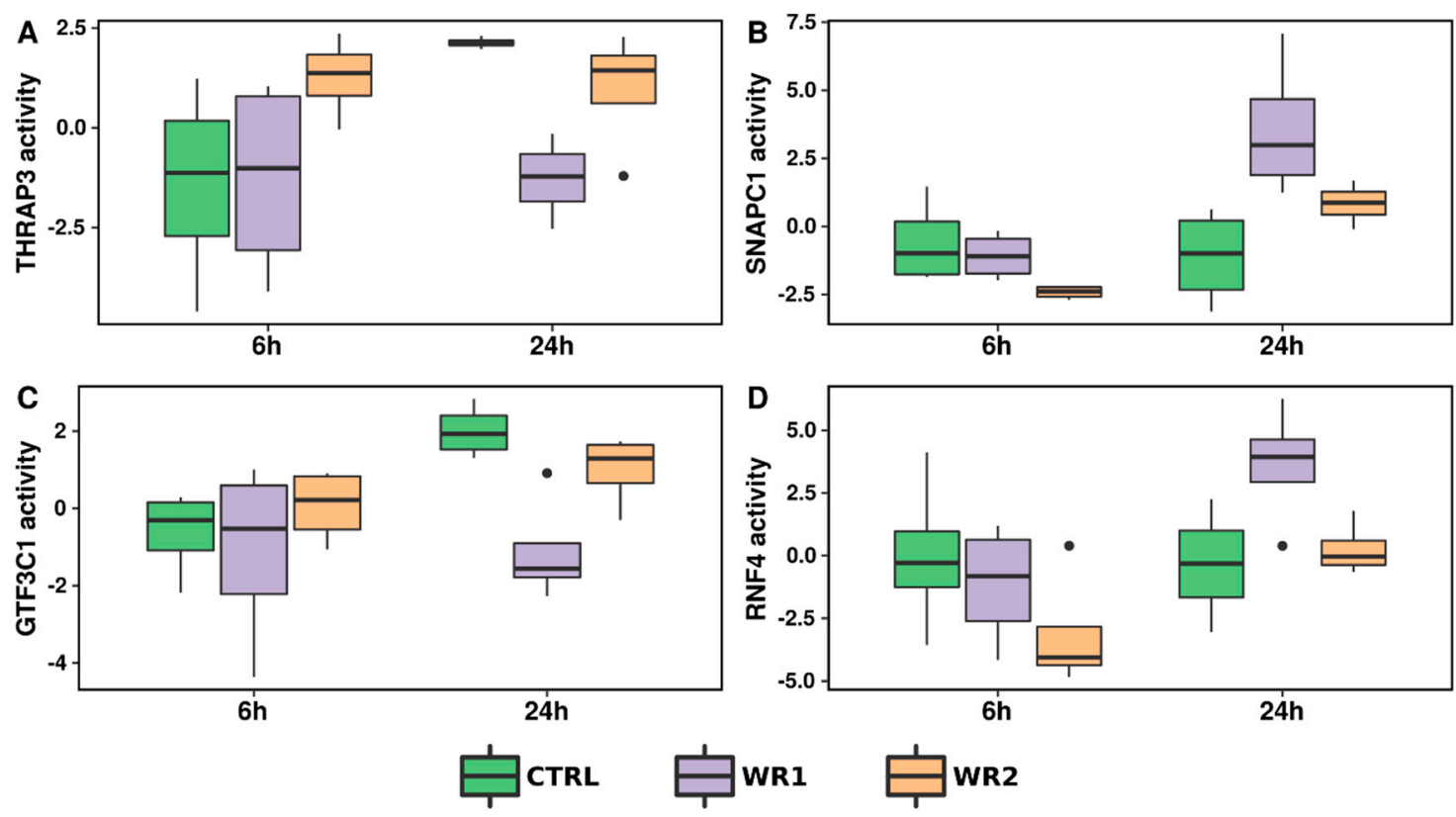

Figure 2. Nominally significant changes of transcription factor (TF) activity in separate comparisons of WR1 vs. WR2 group at 6 (A) or 24 h (B-D) time points. (A) THRAP3; (B) SNAPC1; (C) GTF3C1; (D) RNF4.

For a better estimation of transcription, we took into consideration changes in mRNA expression between the 6 and $24 \mathrm{~h}$ time points, to discover significant differences in TF activity. We found 5 TFs for CTRL, 16 TFs for WR1 and 60 TFs for WR2, with significant differences between 6 and $24 \mathrm{~h}$ (Supplementary Table S4). Interestingly, those five TFs discovered in CTRL (RUFY3, SCMH1, NFIX, ZBTB25 and NFE2L1) were also presented in co-cultures with RWPE1 or RWPE2 (Figure 3) and were activated at similar levels (Supplementary Table S4). Only one TF, RNF4, was unique for RWPE1; moreover, its activity was increased after $24 \mathrm{~h}$ of incubation in WR1 vs. WR2 co-culture. Most of the dysregulated TFs were unique for co-culture with RWPE2 (45 TFs), yet these failed to be differentially activated between the WR1 and WR2 conditions.

The most significant changes were observed after incubation with RWPE2 cells, where 45 TFs were differently activated after $24 \mathrm{~h}$. Since none of these TFs were discovered in 6 or $24 \mathrm{~h}$ comparisons, it is more likely that those TFs have different fluctuation/regulation levels of some pathways. Therefore, we performed the Reactome pathway enrichment analysis using these selected TFs. Significant pathways are presented in Table 2 . 


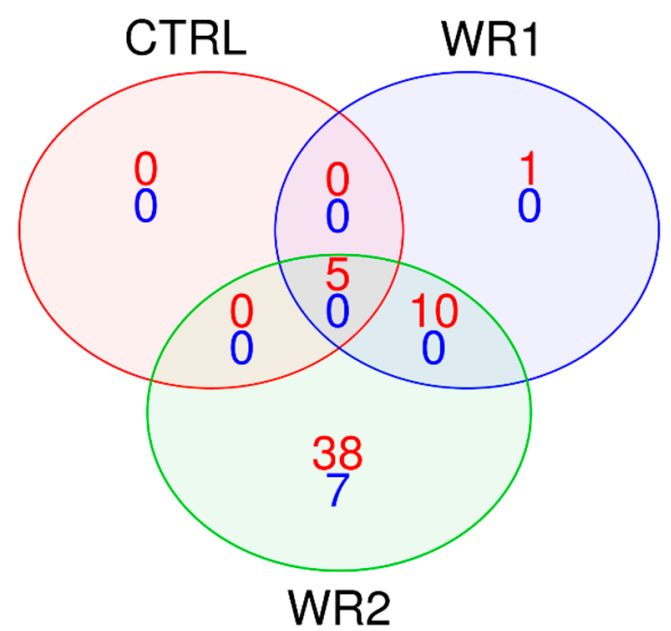

Figure 3. Venn diagram of TFs that changed activity between the 6 and $24 \mathrm{~h}$ time points.

Table 2. Reactome analysis of unique TFs for 6 vs. $24 \mathrm{~h}$ time points in the WR2 condition.

\begin{tabular}{ccccc}
\hline Pathway Identifier & Pathway Name & $\begin{array}{c}\text { Entities } \\
p \text {-Value }\end{array}$ & Entities FDR & TFs \\
\hline R-HSA-8953750 & $\begin{array}{c}\text { Transcriptional Regulation } \\
\text { by E2F6 }\end{array}$ & $2.14 \times 10^{-5}$ & $2.66 \times 10^{-3}$ & YAF2, EED, CBX5 \\
\hline & $\begin{array}{c}\text { RUNX1 interacts with } \\
\text { co-factors whose precise } \\
\text { effect on RUNX1 targets is } \\
\text { not known }\end{array}$ & $3.55 \times 10^{-4}$ & $2.20 \times 10^{-2}$ & $\begin{array}{c}\text { YAF2, SMARCE1, } \\
\text { SMARCA2 }\end{array}$ \\
\hline R-HSA-8943724 & $\begin{array}{c}\text { Regulation of PTEN } \\
\text { gene transcription }\end{array}$ & $1.90 \times 10^{-3}$ & $4.68 \times 10^{-2}$ & EED, REST, SNAI2 \\
\hline R-HSA-3247509 & $\begin{array}{c}\text { Chromatin } \\
\text { modifying enzymes }\end{array}$ & $1.95 \times 10^{-3}$ & $4.68 \times 10^{-2}$ & $\begin{array}{c}\text { SMARCE1, EED, } \\
\text { SMARCA2, REST, KDM5A }\end{array}$ \\
\hline R-HSA-4839726 & $\begin{array}{c}\text { Chromatin organization } \\
\text { R }\end{array}$ & $1.95 \times 10^{-3}$ & $4.68 \times 10^{-2}$ & $\begin{array}{c}\text { SMARCE1, EED, } \\
\text { SMARCA2, REST, KDM5A }\end{array}$ \\
\hline
\end{tabular}

FDR-false discovery rate; TFs—-transcription factors.

\subsection{Validation of IncRNA FER1L4 Expression and miRNA Targets Prediction}

Based on the mRNAseq expression analysis, we discovered overexpression of lncRNA FER1L4 in WPMY1 cell after $24 \mathrm{~h}$ co-culture with RWPE2 cells. Therefore, we ought to validate those results with RT-qPCR. After $24 \mathrm{~h}$ of co-culture, we observed significant upregulation of FER1L4 expression in the WR2 condition in comparison to the CTRL and WR1 conditions (Figure 4).

Since FER1L4 may, in fact, be responsible for the observed dysregulation in the mRNA expression network by acting as competitive endogenous RNA (ceRNA) and sponging multiple micro RNAs (miRNAs), we decided to identify miRNAs which may interact with FER1L4. In the DIANA-LncBase, we found 27 miRNAs with experimentally supported miRNA targets on FER1L4 transcripts (Supplementary Table S5). Then, we performed a Kyoto Encyclopedia of Genes and Genomes (KEGG) enrichment pathways analysis to identify pathways regulated by those miRNAs (Table 3). 


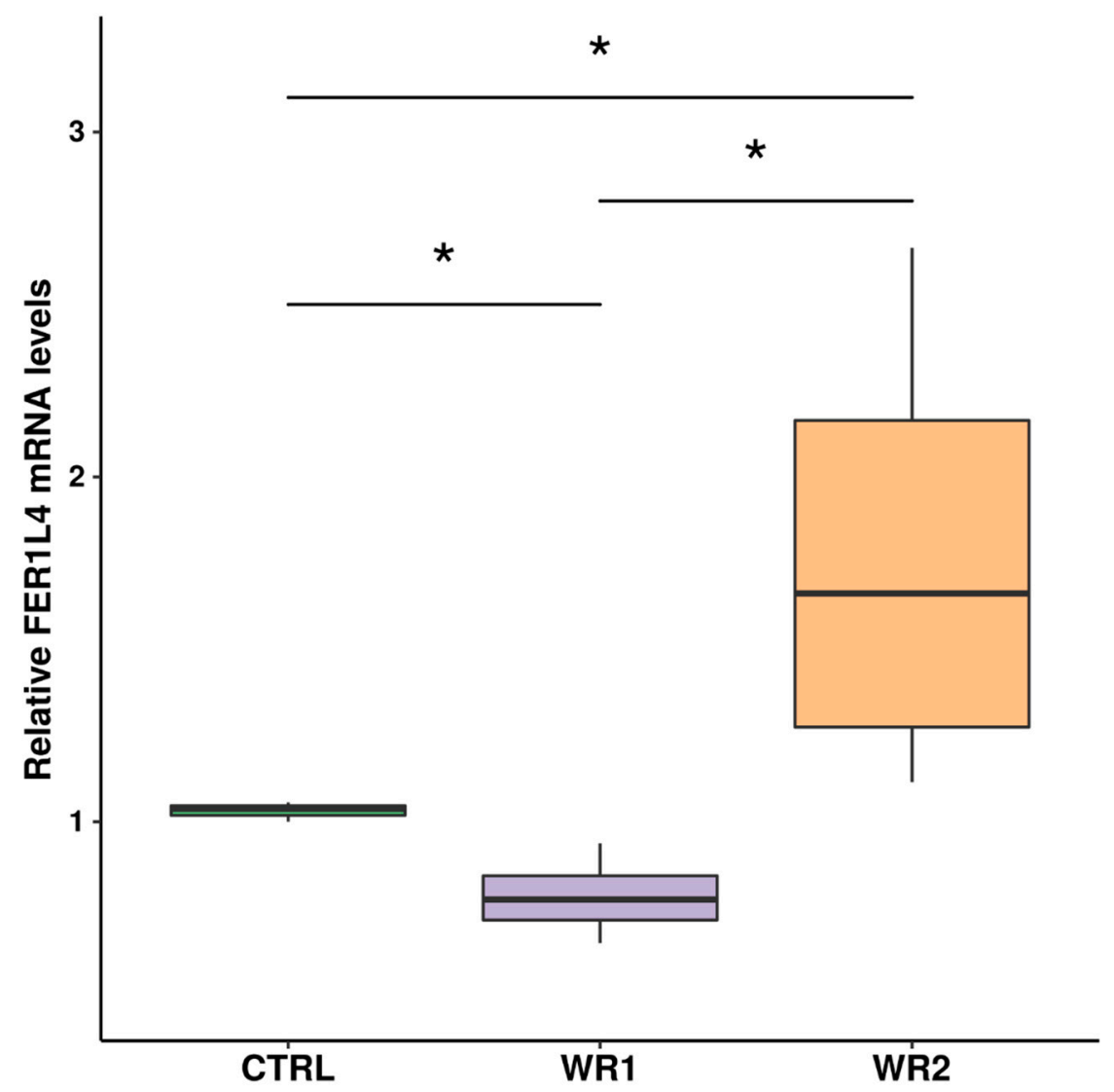

Figure 4. Expression of FER1L4 measured by RT-qPCR in experimental conditions after $24 \mathrm{~h}$ of co-culture. $\left({ }^{*} p<0.05\right.$ by Kruskal-Wallis test).

Table 3. The top 10 KEGG pathways enriched by the target genes of 27 micro RNAs (miRNAs) with experimentally supported interaction with FER1L4.

\begin{tabular}{clccc}
\hline KEGG Pathway & $p$-Value & FDR & $\begin{array}{c}\text { Number } \\
\text { of Genes }\end{array}$ & $\begin{array}{c}\text { Number } \\
\text { of miRNAs }\end{array}$ \\
\hline ECM-receptor interaction (hsa04512) & $6.09 \times 10^{-20}$ & $1.23 \times 10^{-17}$ & 11 & 18 \\
\hline $\begin{array}{c}\text { Signaling pathways regulating } \\
\text { pluripotency of stem cells (hsa04550) }\end{array}$ & $6.91 \times 10^{-6}$ & $6.97 \times 10^{-4}$ & 18 & 12 \\
\hline $\begin{array}{c}\text { Mucin type O-Glycan } \\
\text { biosynthesis (hsa00512) }\end{array}$ & $6.62 \times 10^{-5}$ & $3.63 \times 10^{-3}$ & 4 & 20 \\
\hline Focal adhesion (hsa04510) & $8.23 \times 10^{-5}$ & $3.63 \times 10^{-3}$ & 23 & 23 \\
\hline $\begin{array}{c}\text { PI3K-Akt signaling pathway (hsa04151) } \\
\text { Lysine degradation (hsa00310) }\end{array}$ & $9.13 \times 10^{-5}$ & $3.63 \times 10^{-3}$ & 32 & 19 \\
\hline Glioma (hsa05214) & $2.14 \times 10^{-4}$ & $6.16 \times 10^{-3}$ & 8 & 12 \\
\hline $\begin{array}{c}\text { Glycosphingolipid biosynthesis-lacto } \\
\text { and neolacto series (hsa00601) }\end{array}$ & $2.95 \times 10^{-4}$ & $7.46 \times 10^{-3}$ & 3 & 17 \\
\hline $\begin{array}{c}\text { Adipocytokine signaling } \\
\text { pathway (hsa04920) }\end{array}$ & $6.49 \times 10^{-4}$ & $1.24 \times 10^{-2}$ & 10 & 19 \\
\hline $\begin{array}{c}\text { TGF-beta signaling pathway (hsa04350) } \\
\text { absorption (hsa04974) }\end{array}$ & $7.09 \times 10^{-4}$ & $1.24 \times 10^{-2}$ & 10 & 19 \\
\hline \begin{tabular}{c} 
MAPK signaling pathway (hsa04010) \\
\hline
\end{tabular} & $7.10 \times 10^{-4}$ & $1.24 \times 10^{-2}$ & 12 & 23 \\
\hline
\end{tabular}


Table 3. Cont.

\begin{tabular}{ccccc}
\hline KEGG Pathway & $p$-Value & FDR & $\begin{array}{c}\text { Number } \\
\text { of Genes }\end{array}$ & $\begin{array}{c}\text { Number } \\
\text { of miRNAs }\end{array}$ \\
\hline Nicotine addiction (hsa05033) & $1.05 \times 10^{-3}$ & $1.63 \times 10^{-2}$ & 5 & 17 \\
\hline AMPK signaling pathway (hsa04152) & $1.55 \times 10^{-3}$ & $2.24 \times 10^{-2}$ & 13 & 17 \\
\hline mTOR signaling pathway (hsa04150) & $1.75 \times 10^{-3}$ & $2.36 \times 10^{-2}$ & 9 & 18 \\
\hline ErbB signaling pathway (hsa04012) & $1.96 \times 10^{-3}$ & $2.48 \times 10^{-2}$ & 10 & 21 \\
\hline Amoebiasis (hsa05146) & $2.23 \times 10^{-3}$ & $2.63 \times 10^{-2}$ & 7 & 13 \\
\hline Melanoma (hsa05218) & $2.35 \times 10^{-3}$ & $2.63 \times 10^{-2}$ & 9 & 18 \\
\hline Proteoglycans in cancer (hsa05205) & $2.69 \times 10^{-3}$ & $2.86 \times 10^{-2}$ & 16 & 21 \\
\hline Pancreatic cancer (hsa05212) & $4.09 \times 10^{-3}$ & $4.03 \times 10^{-2}$ & 8 & 12 \\
\hline Wnt signaling pathway (hsa04310) & $4.19 \times 10^{-3}$ & $4.03 \times 10^{-2}$ & 14 & 20
\end{tabular}

FDR—false discovery rate.

\section{Discussion}

In this study, we investigate changes in TF activity after exposing fibroblasts to normal epithelial cells (RWPE1) or cells with cancer phenotype (RWPE2). The co-culture of fibroblasts with normal epithelial cells (WR1 condition) results in the activation of two TFs, RNF4 and SNAPC1. In the WR2 condition co-culture with the cancerous cell line, activation of GTF3C1 and THRAP3 can be seen. The pathway analysis, performed with Reactome, showed that dysregulated TF activity in CAF transformation could be associated with the PTEN and the RUNX1 associated pathways. Additionally, we explored the potential role of the identified DE gene, FER1L4, in sponging multiple miRNAs, that could, at least partially, be responsible for observed transcript expression dysregulation. In general, our observations are consistent with those of other researchers, who showed that interactions of normal fibroblasts with epithelial cells are associated with a proinflammatory response, whereas the co-culture with cancer epithelial cells is associated with transformation and increased motility of fibroblasts.

Two of the discovered TFs, SNAPC1 and GTF3C1, are associated with DNA-binding Pol III regulated transcription [18]. Interestingly, SNAPC1 activity is higher after co-culture with RWPE1 (normal cells), whereas GTF3C1 activity is higher after co-culture with RWPE2 (cancerous cells). Therefore, this could lead to two different transcription patterns associated with DNA-binding Pol III regulated transcription. Possibly, co-culture of fibroblasts with normal epithelial cells and preferential activation by SNAPC1 TF may promote synthesis of small nuclear RNAs [19], which is responsible for the processing of the primary transcription products of split genes, thus allowing precise alignment and correct excision of introns. Conversely, preferential activation of GTF3C1 in co-culture with transformed epithelial cells may lead to increased ribosome biogenesis and protein synthesis [20] with tumor promoting effects. Thus, changes in TF usage during co-culture may represent an effect of trading by fibroblast precision for efficiency in changed co-culture conditions.

Another TF, RNF4, which was activated after co-culture with normal epithelium, is a small ubiquitin-like modifier (SUMO)-targeting RING domain ubiquitin ligase that directly connects the SUMO and the ubiquitin pathways, resulting in the proteasomal degradation of poly-SUMO-modified substrates [21]. RNF4, along with the transcription repressor ZNF278/PATZ, may regulate steroid receptor-dependent transcription activated by androgen receptor [22,23]. Moreover, silencing RNF4 potentiates TGF- $\beta 1$ expression and activity [24] and TNF- $\alpha$ - and IL-1 $\beta$-induced NF- $\kappa$ B activation [25]. 
At the same time, lung myofibroblast differentiation was shown to be potentiated by TGF- $\beta$ which can act through TGF- $\beta 1 /$ Smad2 and NF-KB signaling pathways [26].

In our study, after incubation with normal epithelium, we observed upregulated expression of MMP-3. The results by Hsieh et al. [27] showed that expression of MMP-3 was lower in CAFs than in fibroblasts derived from normal tissue. Moreover, they suggest that NF- $\mathrm{B}$ may contribute to reactive oxygen species (ROS)-mediated human MMP-3 suppression in CAFs through interaction with ZBP-89 or other transcriptional repressors. In another study, the NF- $\mathrm{kB}$ inhibitor, pyrrolidine dithiocarbamate (PDTC), reduced HMGB1-induced TGF- $\beta 1$ release and fibroblast to myofibroblast differentiation of lung fibroblasts [28], one of the NF- $\mathrm{KB}$ targets in THRAP3, a TF which, in our study, was activated after co-culture with RWPE2 cells.

Our pathway analysis of 45 unique TFs differently activated after incubation with RWPE2 cells showed two main pathways that could be associated with CAF transformation. One of the identified pathways is associated with regulation of PTEN transcription and the other with the regulation of RUNX1 associated transcription. Interestingly, one of the DE genes between the WR1 and WR2 conditions was fer-1-like family member 4 pseudogene (lncRNA-FER1L4). It was shown that FER1L4 can act as a sponge for miR-106a-5p and, therefore, regulate the PTEN expression [29]. Further experiments demonstrated that FER1L4 downregulation leads to decreases in both RUNX1 and PTEN mRNA and protein levels, possibly via sponging miR-106a-5p [30]. However, other papers suggest that RUNX1 and PTEN might have opposite effects in TGF- $\beta$-induced myofibroblast differentiation. White et al. [31] showed that PTEN inhibits myofibroblast differentiation in vitro, although the effect was abolished after TGF- $\beta$ exposure. However, the latest studies have shown that the promotion of TGF- $\beta$ induced myofibroblast differentiation via the downregulation of PTEN may be regulated by miR-216a [32]. On the other side, RUNX1 modulates the cellular response to TGF- $\beta$ and promotes myofibroblast differentiation in both marrow-derived and tissue-resident mesenchymal stem cells [33]. Lin et al. [34] also showed that RUNX1 can promote fibroblast activation and increase $\alpha$-SMA and fibronectin expression. Additional analysis showed that FER1L4 can induce dysregulation of pathways discovered in TF analysis by acting as ceRNA. The sponging of miRNAs by FER1L4 was studied in multiple cancers, including prostate [35] and intestine [36], but it was never observed in CAFs. Therefore, this provides a novel insight in the CAF transformation and shows a potential role of FER1L4 in the regulation of the CAF transformation. Several pathways regulated by miRNA sponged by FER1L4, such as the PI3K-Akt signaling pathway and the TGF-beta signaling pathway, relate to the PTEN and RUNX1 pathways from TF analysis. Our study has several limitations-the major one is that there is only one biological replicate in one in vitro model. Moreover, in light of the current results, one may postulate that the two time points chosen for analysis are not sufficient to describe the transcriptional background of the process of transformation from normal epithelial cells to CAFs. Additional functional analyses (e.g., siRNA or use of inhibitors) are necessary to confirm the obtained results.

We cannot exclude the possibility that, due to these limitations, we did not avoid false negative results. However, we hope that extensive and rigorous statistical analyses let us minimize the chance of false positive conclusions.

Our results demonstrated that CAF transformation can be orchestrated by multiple TFs. We showed pathways associated with PTEN and RUNX1 that could be involved in crosstalk between fibroblasts and epithelial cells in healthy tissue, as well as those associated with tumorigenesis. Moreover, we showed that observed initiation of CAF transformation could be orchestrated by lncRNA-FER1L4, which, by sponging multiple miRNAs, may regulate mRNA expression. Although, further investigations are needed to characterize the crosstalk between pathways and their TFs, which might have profound implications to oncogenesis and anticancer therapies. The crosstalk between molecular pathways at the early stage of CAF transformation could lead to the discovery of regulatory points and developing of new methods in the fight against cancer. Moreover, the identification of the signaling pathways that are activated under specific conditions is crucial for precision medicine development. 


\section{Materials and Methods}

\subsection{Cell Lines and Cell Culture}

The WPMY1 (human prostatic myofibroblast stromal cell line from the histological normal adult prostate), RWPE1 (human prostatic epithelial cell line derived from the same peripheral zone of the prostate as WPMY1) and RWPE2 (v-Ki-Ras-induced tumorigenic cell line derived from RWPE1) cell lines were obtained from American Type Culture collection-ATCC (CRL-2854, CRL-11609 and CRL-11610, respectively). WPMY1 cells were maintained in Dulbecco's Modified Eagle's Medium/Nutrient Mixture F-12 (DMEM/F12, cat.no. 10565018) supplemented with 5\% fetal bovine serum (FBS, cat.no. 10500064), and 1\% penicillin/streptomycin antibiotic solution (cat.no. 15140122). RWPE1 and RWPE2 cells were maintained in keratinocyte serum-free medium supplemented with $0.05 \mathrm{mg} / \mathrm{mL}$ bovine pituitary extract and $5 \mathrm{ng} / \mathrm{mL}$ recombinant epidermal growth factor (K-SFM, no. 17005042). Medium was changed every 2-3 days. All materials were purchased from Thermo Fisher Scientific (Waltham, MA, USA) unless mentioned otherwise. Cells were grown in an incubator at a temperature of $37^{\circ} \mathrm{C}$ at $5 \% \mathrm{CO}_{2}$.

\subsection{Indirect Coculture of WPMY1 and RWPE1 or RWPE2}

WPMY1 cells were seeded in 6-well plates at a density of $4 \times 105$ cells per well in growth medium. RWPE1 and RWPE2 cells were seeded on 0.4- $\mu$ m pore size tissue-culture inserts formatted for 6-well plates (cat.no. 83.3930.040, Sarstedt, Numbrecht, Germany), at a density of $3 \times 10^{5}$ and $4 \times 10^{5}$ cells per insert, respectively. After 2 days of separate culture, all cells were starved in FBS-free, antibiotic-supplemented DMEM/F12 medium for $24 \mathrm{~h}$. Then, inserts with RWPE1 and RWPE2 cells were added to 6-well plates with WPMY1 cells, for 6 or $24 \mathrm{~h}$. As a control, we used a WPMY1 culture without addition of an insert. As a result, we obtained three experimental conditions: WPMY1 alone, WPMY + RWPE1 (WR1) and WPMY + RWPE2 (WR2), resulting in 6 replicates of each condition per time point.

\subsection{RNA Isolation and $m R N A$ Sequencing}

Total RNA was extracted from cells using the ReliaPrep RNA MiniPrep System (Promega, Madison, WI, USA). RNA quality and integrity were assessed using TapeStation (Agilent, Santa Clara, CA, USA). Four out of 6 replicates with highest RNA integrity values (RIN) and RNA concentrations were used to prepare mRNA sequencing libraries using the Sense mRNA-Seq Library prep Kit v2 (Lexogen, Vienna, Austria) according to the manufacturer's protocol. Briefly, after RNA normalization, $1.5 \mu \mathrm{g}$ of RNA was denatured, polyA-selected on magnetic beads and purified. After reverse transcription, cDNA was indexed and amplified in 12 PCR cycles. Twenty-four individual libraries were pooled, at $1.8 \mathrm{pM}$ final concentration, for a 150-cycle NextSeq high-output flow cell. Paired-end sequencing of $2 \times 75 \mathrm{bp}$ was performed on a NextSeq 500 platform (Illumina, San Diego, CA, USA).

\subsection{NGS Data Preparation}

Raw Illumina's Base Call (BCL) files from a paired-end mRNA sequencing run were demultiplexed and converted into fastq files with Illumina Bcl2Fastq v.2.20.0.422 software. The quality of the reads was assessed using FastQC v.11.8. (http://www.bioinformatics.babraham.ac.uk/projects/fastqc/). After removing, with Cutadapt v.1.18 [37], the starter/stopper heterodimer sequence from reads, according to the kit manufacturer's instructions, we aligned the reads to a reference genome GRCh38, ensembl version 95, with STAR aligner v.2.7.0c [38], using a two-pass method. The reads mapped to each gene were enumerated using HT-Seq-count v.0.11.2 [39] with ensembl version 95 for gene annotation. Quality assessment of alignment and enumerated gene expression levels was performed using MultiQC v.1.9 [40]. Raw expression values provided in a tab-delimited format were then uploaded into $\mathrm{R}$ for further analysis. The raw mRNA sequences, along with raw counts from HTSeq software, were deposited in GEO (GSE159493). 


\section{5. mRNA-seq Analysis}

The raw reads aligned to particular mRNAs were transformed using the voom function in the package 'limma' [41]. Subsequently, two surrogate variables were estimated using the sva package in R. Due to the limited sample size, we set the number of confounders to two. All following differential expression analysis were performed with the 'limma' package in $\mathrm{R}$ statistical environment on the residuals of the read counts from the linear model with two independent variables (both estimated surrogate variables).

At the beginning, we performed standard pairwise comparisons between WPMY1 cells and co-cultures with RWPE1 or RWPE2 after 6 or $24 \mathrm{~h}$ of incubation, separately. Then, to analyze the difference between co-cultures in the context of the time points, we looked at the change in the expression in time in every group to determine which transcripts changed expression in every experimental condition. Therefore, using the lmFit function in 'limma', we tested contrasts between time points $(24-6 \mathrm{~h})$ in each condition.

\subsection{TFs Estimation Analysis}

TF activity was calculated using the SEPIRA (Systems EPigenomics Inference of Regulatory Activity) package [42] using mRNA expression patterns. First, we constructed a fibroblast-specific network of TFs using GTEx v7 RNA-seq of 483 cultured fibroblasts [43]. Then, we reduced the number of TFs to the top-ranking 100 factors which are involved in regulation of transcription in normal fibroblasts from GTEx. Next, we calculated the TF activity score of the constructed network from mRNA-seq expression data from our samples. Scores with $>1$ referred to positive regulation, $<-1$ to negative regulation and from 1 to -1 to no regulation. Differentially activated TFs between time points in every group were estimated with the 'limma' package in $\mathrm{R}$ statistical environment. To analyze differences between co-cultures in the context of the time points, we used the same contrasts as for mRNA expression.

\subsection{RT-qPCR Validation of FER1L4 Expression}

The lncRNA-FER1L4 expression was validated with RT-qPCR. Reverse transcription was performed with SuperScript III Reverse Transcriptase (Thermo Fisher Scientific, Waltham, MA, USA), according to the manufacturer's instructions, with 1 ug of RNA and a mix of oligo(dT) 20 and random hexamers ( $2 \mu \mathrm{M}$ each, E0105-01, E0101-01, EURx, Gdansk, Poland). The generated cDNA template was diluted 10 times. The qPCR reaction was performed in $25 \mu \mathrm{L}$ volume with Fast Probe qPCR Master Mix master mix (E0422-03, EURx, Gdansk, Poland), $4 \mu \mathrm{L}$ of cDNA template and $1.25 \mu \mathrm{L}$ of taqman probes (Hs00957061_m1 for FER1L4 or Hs02786624_g1 for GAPDH, Thermo Fisher Scientific, Waltham, MA, USA). The cycling conditions were $95^{\circ} \mathrm{C}$ for $3 \mathrm{~min}$, followed by 40 cycles of $95^{\circ} \mathrm{C}$ for $10 \mathrm{~s}$ and $60^{\circ} \mathrm{C}$ for $30 \mathrm{~s}$. Each qPCR reaction was performed in triplicate. Raw $\mathrm{Cq}$ values were processed in CFX Maestro software (Biorad, Hercules, CA, USA). The expression was calculated with the $\Delta \Delta \mathrm{Cq}$ method with, GAPDH as a reference gene. Statistical analysis was conducted in R.

\subsection{FER1L4-miRNA Interaction and KEGG Pathway Analysis}

The experimentally supported interactions of the FER1L4-miRNA were checked in DIANA-LncBase v3 database [44,45]. Discovered miRNAs where then uploaded to DIANA-mirPath [46] to find targeted genes with the DIANA-microT-CDS algorithm [47] and KEGG pathway enrichment analysis. List of the significant KEGG pathways regulated by miRNAs, which interacted with FER1L4 was compared with previous analysis to find potential common regulatory pathways.

Supplementary Materials: Supplementary Materials can be found at http://www.mdpi.com/1422-0067/21/22/ 8749/s1. Supplementary Table S1. DE genes between WPMY1 cells and WPMY1 cocultured with RWPE1; Supplementary Table S2. DE genes between $6 \mathrm{~h}$ and $24 \mathrm{~h}$ incubation time points in each of the experimental conditions; Supplementary Table S3. Significant topGO pathways (BP) for unique DE genes in WR1 and WR2 
conditions separately; Supplementary Table S4. Statistically significant TFs activity between $6 \mathrm{~h}$ and $24 \mathrm{~h}$ incubation time points in each of the experimental conditions. Supplementary Table S5. Experimentally validated interactions of FER1L4 with miRNAs in DIANA-LncBase v3.

Author Contributions: P.K., A.B., J.T.-Ż., P.P.W. and M.T.S. designed the research; J.D.-L., A.B. and P.S.K. performed the research; J.T.-Ż. prepared the sequencing libraries; P.K. and M.T.S. analyzed the data; P.K., J.T.-Ż., P.P.W. and M.T.S. interpreted the data; P.K., P.P.W. and M.T.S. wrote the paper. All authors contributed to critical revision of the manuscript and approved its publication. All authors have read and agreed to the published version of the manuscript.

Funding: This research was funded by the National Science Centre (Poland), grant No. 2017/01/X/NZ3/01158 (to P.K.).

Acknowledgments: The bioinformatics analysis was performed using the Prometheus supercomputer (AGH, Krakow, Poland), which was funded by PLGrid Infrastructure.

Conflicts of Interest: The authors declare no conflict of interest.

\section{Abbreviations}

$\begin{array}{ll}\alpha \text {-SMA } & \text { Alpha smooth muscle actin } \\ \text { ceRNA } & \text { Competitive endogenous RNA } \\ \text { CAFs } & \text { Cancer-associated fibroblasts } \\ \text { CXCL12 } & \text { Stromal cell-derived factor 1(SDF1) } \\ \text { ECM } & \text { Extracellular matrix } \\ \text { EGFR } & \text { Epidermal growth factor receptor } \\ \text { ERK } & \text { Extracellular signal regulated kinase } \\ \text { FER1L4 } & \text { Fer-1 like family member 4 } \\ \text { IL-1 } & \text { Interleukin 1 } \\ \text { lncRNA } & \text { Long non-coding RNA } \\ \text { TNF- } \alpha & \text { Tumor necrosis factor alpha } \\ \text { RUNX1 } & \text { Runt related transcription factor 1 } \\ \text { TGF- } \beta & \text { Transforming growth factor beta }\end{array}$

\section{References}

1. Gieniec, K.A.; Butler, L.M.; Worthley, D.L.; Woods, S.L. Cancer-associated fibroblasts-heroes or villains? Br. J. Cancer 2019, 121, 293-302. [CrossRef]

2. Sahai, E.; Astsaturov, I.; Cukierman, E.; DeNardo, D.G.; Egeblad, M.; Evans, R.M.; Fearon, D.; Greten, F.R.; Hingorani, S.R.; Hunter, T.; et al. A framework for advancing our understanding of cancer-associated fibroblasts. Nat. Rev. Cancer. 2020, 20, 174-186. [CrossRef]

3. Räsänen, K.; Vaheri, A. Activation of fibroblasts in cancer stroma. Exp Cell Res. 2010, 316, $2713-2722$. [CrossRef]

4. Micallef, L.; Vedrenne, N.; Billet, F.; Coulomb, B.; Darby, I.A.; Desmoulière, A. The myofibroblast, multiple origins for major roles in normal and pathological tissue repair. Fibrogenesis Tissue Repair 2012, 5, S5. [CrossRef]

5. Wen, S.; Niu, Y.; Yeh, S.; Chang, C. BM-MSCs promote prostate cancer progression via the conversion of normal fibroblasts to cancer-associated fibroblasts. Int. J. Oncol. 2015, 47, 719-727. [CrossRef]

6. Cho, N.; Razipour, S.E.; McCain, M.L. Featured Article: TGF- $\beta 1$ dominates extracellular matrix rigidity for inducing differentiation of human cardiac fibroblasts to myofibroblasts. Exp. Biol. Med. 2018, 243, 601-612. [CrossRef]

7. Casey, T.M.; Eneman, J.; Crocker, A.; White, J.; Tessitore, J.; Stanley, M.; Harlow, S.; Bunn, J.Y.; Weaver, D.; Muss, H.; et al. Cancer associated fibroblasts stimulated by transforming growth factor beta1 (TGF-beta 1) increase invasion rate of tumor cells: A population study. Breast Cancer Res. Treat. 2008, 110, 39-49. [CrossRef]

8. Labernadie, A.; Kato, T.; Brugués, A.; Serra-Picamal, X.; Derzsi, S.; Arwert, E.; Weston, A.; González-Tarragó, V.; Elosegui-Artola, A.; Albertazzi, L.; et al. A mechanically active heterotypic E-cadherin/ $\mathrm{N}$-cadherin adhesion enables fibroblasts to drive cancer cell invasion. Nat. Cell Biol. 2017, 19, 224-237. [CrossRef]

9. Kalluri, R. The biology and function of fibroblasts in cancer. Nat. Rev. Cancer. 2016, 16, 582-598. [CrossRef] 
10. Elyada, E.; Bolisetty, M.; Laise, P.; Flynn, W.F.; Courtois, E.T.; Burkhart, R.A.; Teinor, J.A.; Belleau, P.; Biffi, G.; Lucito, M.S.; et al. Cross-Species Single-Cell Analysis of Pancreatic Ductal Adenocarcinoma Reveals Antigen-Presenting Cancer-Associated Fibroblasts. Cancer Discov. 2019, 9, 1102-1123. [CrossRef]

11. Costa, A.; Kieffer, Y.; Scholer-Dahirel, A.; Pelon, F.; Bourachot, B.; Cardon, M.; Sirven, P.; Magagna, I.; Fuhrmann, L.; Bernard, C.; et al. Fibroblast Heterogeneity and Immunosuppressive Environment in Human Breast Cancer. Cancer Cell 2018, 33, 463-479.e10. [CrossRef] [PubMed]

12. Biffi, G.; Oni, T.E.; Spielman, B.; Hao, Y.; Elyada, E.; Park, Y.; Preall, J.; Tuveson, D.A. IL1-Induced JAK/STAT Signaling Is Antagonized by TGF $\beta$ to Shape CAF Heterogeneity in Pancreatic Ductal Adenocarcinoma. Cancer Discov. 2019, 9, 282-301. [CrossRef] [PubMed]

13. Kojima, Y.; Acar, A.; Eaton, E.N.; Mellody, K.T.; Scheel, C.; Ben-Porath, I.; Onder, T.T.; Wang, Z.C.; Richardson, A.L.; Weinberg, R.A.; et al. Autocrine TGF-beta and stromal cell-derived factor-1 (SDF-1) signaling drives the evolution of tumor-promoting mammary stromal myofibroblasts. Proc. Natl. Acad. Sci. USA 2010, 107, 20009-20014. [CrossRef] [PubMed]

14. Neuzillet, C.; de Gramont, A.; Tijeras-Raballand, A.; de Mestier, L.; Cros, J.; Faivre, S.; Raymond, E. Perspectives of TGF- $\beta$ inhibition in pancreatic and hepatocellular carcinomas. Oncotarget 2014, 5, 78-94. [CrossRef] [PubMed]

15. Derynck, R.; Zhang, Y.E. Smad-dependent and Smad-independent pathways in TGF-beta family signalling. Nature 2003, 425, 577-584. [CrossRef]

16. Bierie, B.; Moses, H.L. Tumour microenvironment: TGFbeta: The molecular Jekyll and Hyde of cancer. Nat. Rev. Cancer 2006, 6, 506-520. [CrossRef]

17. Yoshida, G.J. Regulation of heterogeneous cancer-associated fibroblasts: The molecular pathology of activated signaling pathways. J. Exp. Clin. Cancer Res. 2020, 39, 112. [CrossRef]

18. Durrieu-Gaillard, S.; Dumay-Odelot, H.; Boldina, G.; Tourasse, N.J.; Allard, D.; André, F.; Macari, F.; Choquet, A.; Lagarde, P.; Drutel, G.; et al. Regulation of RNA polymerase III transcription during transformation of human IMR90 fibroblasts with defined genetic elements. Cell Cycle 2018, 17, 605-615. [CrossRef]

19. Ford, E.; Hernandez, N. Characterization of a trimeric complex containing Oct-1, SNAPc, and DNA. J. Biol. Chem. 1997, 272, 16048-16055. [CrossRef]

20. Tsai, Y.-C.; Greco, T.M.; Cristea, I.M. Sirtuin 7 plays a role in ribosome biogenesis and protein synthesis. Mol. Cell Proteom. 2014, 13, 73-83. [CrossRef]

21. Sun, H.; Hunter, T. Poly-small ubiquitin-like modifier (PolySUMO)-binding proteins identified through a string search. J. Biol. Chem. 2012, 287, 42071-42083. [CrossRef]

22. Moilanen, A.M.; Poukka, H.; Karvonen, U.; Häkli, M.; Jänne, O.A.; Palvimo, J.J. Identification of a novel RING finger protein as a coregulator in steroid receptor-mediated gene transcription. Mol. Cell Biol. 1998, 18, 5128-5139. [CrossRef]

23. Pero, R.; Lembo, F.; Palmieri, E.A.; Vitiello, C.; Fedele, M.; Fusco, A.; Bruni, C.B.; Chiariotti, L. PATZ attenuates the RNF4-mediated enhancement of androgen receptor-dependent transcription. J. Biol. Chem. 2002, 277, 3280-3285. [CrossRef]

24. Liu, Y.; Zhao, D.; Qiu, F.; Zhang, L.-L.; Liu, S.-K.; Li, Y.-Y.; Liu, M.T.; Wu, D.; Wang, J.X.; Ding, X.Q.; et al. Manipulating PML SUMOylation via Silencing UBC9 and RNF4 Regulates Cardiac Fibrosis. Mol. Ther. 2017, 25, 666-678. [CrossRef]

25. Tan, B.; Mu, R.; Chang, Y.; Wang, Y.B.; Wu, M.; Tu, H.Q.; Zhang, Y.C.; Guo, S.S.; Qin, X.H.; Li, T.; et al. RNF4 negatively regulates NF-kB signaling by down-regulating TAB2. FEBS Lett. 2015, 589, 2850-2858. [CrossRef]

26. Zhang, Q.; Tu, W.; Tian, K.; Han, L.; Wang, Q.; Chen, P.; Zhou, X. Sirtuin 6 inhibits myofibroblast differentiation via inactivating transforming growth factor- $\beta 1 / \mathrm{Smad} 2$ and nuclear factor- $\mathrm{k} B$ signaling pathways in human fetal lung fibroblasts. J. Cell Biochem. 2019, 120, 93-104. [CrossRef]

27. Hsieh, C.-L.; Liu, C.-M.; Chen, H.-A.; Yang, S.-T.; Shigemura, K.; Kitagawa, K.; Yamamichi, F.; Fujisawa, M.; Liu, Y.R.; Lee, W.H.; et al. Reactive oxygen species-mediated switching expression of MMP-3 in stromal fibroblasts and cancer cells during prostate cancer progression. Sci. Rep. 2017, 7, 9065. [CrossRef]

28. Wang, Q.; Wang, J.; Wang, J.; Hong, S.; Han, F.; Chen, J.; Chen, G. HMGB1 induces lung fibroblast to myofibroblast differentiation through NF-kB-mediated TGF- $\beta 1$ release. Mol. Med. Rep. 2017, 15, 3062-3068. [CrossRef] 
29. Xia, T.; Chen, S.; Jiang, Z.; Shao, Y.; Jiang, X.; Li, P.; Xiao, B.; Guo, J. Long noncoding RNA FER1L4 suppresses cancer cell growth by acting as a competing endogenous RNA and regulating PTEN expression. Sci. Rep. 2015, 5, 13445. [CrossRef]

30. Liu, Z.; Shao, Y.; Tan, L.; Shi, H.; Chen, S.; Guo, J. Clinical significance of the low expression of FER1L4 in gastric cancer patients. Tumour Biol. 2014, 35, 9613-9617. [CrossRef]

31. White, E.S.; Atrasz, R.G.; Hu, B.; Phan, S.H.; Stambolic, V.; Mak, T.W.; Hogaboam, C.M.; Flaherty, K.R.; Martinez, F.J.; Kontos, C.D.; et al. Negative regulation of myofibroblast differentiation by PTEN (Phosphatase and Tensin Homolog Deleted on chromosome 10). Am. J. Respir. Crit. Care Med. 2006, 173, 112-121. [CrossRef]

32. Qu, C.; Liu, X.; Ye, T.; Wang, L.; Liu, S.; Zhou, X.; Wu, G.; Lin, J.; Shi, S.; Yang, B. miR-216a exacerbates TGF- $\beta$-induced myofibroblast transdifferentiation via PTEN/AKT signaling. Mol. Med. Rep. 2019, 19, 5345-5352. [CrossRef]

33. Kim, W.; Barron, D.A.; San Martin, R.; Chan, K.S.; Tran, L.L.; Yang, F.; Ressler, S.J.; Rowley, D.R. RUNX1 is essential for mesenchymal stem cell proliferation and myofibroblast differentiation. Proc. Natl. Acad. Sci. USA 2014, 111, 16389-16394. [CrossRef]

34. Lin, S.; Zhang, R.; Xu, L.; Ma, R.; Xu, L.; Zhu, L.; Hu, J.; An, X. LncRNA Hoxaas3 promotes lung fibroblast activation and fibrosis by targeting miR-450b-5p to regulate Runx1. Cell Death Dis. 2020, 11, 706. [CrossRef]

35. Gao, X.; Wang, N.; Wu, S.; Cui, H.; An, X.; Yang, Y. Long non-coding RNA FER1L4 inhibits cell proliferation and metastasis through regulation of the PI3K/AKT signaling pathway in lung cancer cells. Mol. Med. Rep. 2019, 20, 182-190. [CrossRef] [PubMed]

36. Yue, B.; Sun, B.; Liu, C.; Zhao, S.; Zhang, D.; Yu, F.; Yan, D. Long non-coding RNA Fer-1-like protein 4 suppresses oncogenesis and exhibits prognostic value by associating with miR-106a-5p in colon cancer. Cancer Sci. 2015, 106, 1323-1332. [CrossRef]

37. Martin, M. Cutadapt removes adapter sequences from high-throughput sequencing reads. EMBnet J. 2011, 17, 10. [CrossRef]

38. Dobin, A.; Davis, C.A.; Schlesinger, F.; Drenkow, J.; Zaleski, C.; Jha, S.; Batut, P.; Chaisson, M.; Gingeras, T.R. STAR: Ultrafast universal RNA-seq aligner. Bioinformatics 2013, 29, 15-21. [CrossRef]

39. Anders, S.; Pyl, P.T.; Huber, W. HTSeq-A Python framework to work with high-throughput sequencing data. Bioinformatics 2015, 31, 166-169. [CrossRef]

40. Ewels, P.; Magnusson, M.; Lundin, S.; Käller, M. MultiQC: Summarize analysis results for multiple tools and samples in a single report. Bioinformatics 2016, 32, 3047-3048. [CrossRef]

41. Ritchie, M.E.; Phipson, B.; Wu, D.; Hu, Y.; Law, C.W.; Shi, W.; Smyth, G.K. limma powers differential expression analyses for RNA-sequencing and microarray studies. Nucleic Acids Res. 2015, 43, e47. [CrossRef] [PubMed]

42. Chen, Y.; Widschwendter, M.; Teschendorff, A.E. Systems-epigenomics inference of transcription factor activity implicates aryl-hydrocarbon-receptor inactivation as a key event in lung cancer development. Genome Biol. 2017, 18, 236. [CrossRef] [PubMed]

43. Carithers, L.J.; Ardlie, K.; Barcus, M.; Branton, P.A.; Britton, A.; Buia, S.A.; Compton, C.C.; DeLuca, D.S.; Peter-Demchok, J.; Gelfand, E.T.; et al. A Novel Approach to High-Quality Postmortem Tissue Procurement: The GTEx Project. Biopreserv. Biobanking 2015, 13, 311-319. [CrossRef] [PubMed]

44. Paraskevopoulou, M.D.; Karagkouni, D.; Vlachos, I.S.; Tastsoglou, S.; Hatzigeorgiou, A.G. microCLIP super learning framework uncovers functional transcriptome-wide miRNA interactions. Nat Commun. 2018, 9, 3601. [CrossRef] [PubMed]

45. Karagkouni, D.; Paraskevopoulou, M.D.; Tastsoglou, S.; Skoufos, G.; Karavangeli, A.; Pierros, V.; Zacharopoulou, E.; Hatzigeorgiou, A.G. DIANA-LncBase v3, indexing experimentally supported miRNA targets on non-coding transcripts. Nucleic Acids Res. 2019, 48, D101-D110. [CrossRef] 
46. Vlachos, I.S.; Zagganas, K.; Paraskevopoulou, M.D.; Georgakilas, G.; Karagkouni, D.; Vergoulis, T.; Dalamagas, T.; Hatzigeorgiou, A.G. DIANA-miRPath v3.0, deciphering microRNA function with experimental support. Nucleic Acids Res. 2015, 43, W460-W466. [CrossRef]

47. Reczko, M.; Maragkakis, M.; Alexiou, P.; Grosse, I.; Hatzigeorgiou, A.G. Functional microRNA targets in protein coding sequences. Bioinformatics 2012, 28, 771-776. [CrossRef]

Publisher's Note: MDPI stays neutral with regard to jurisdictional claims in published maps and institutional affiliations.

(C) 2020 by the authors. Licensee MDPI, Basel, Switzerland. This article is an open access article distributed under the terms and conditions of the Creative Commons Attribution (CC BY) license (http://creativecommons.org/licenses/by/4.0/). 